\title{
ANALISIS LAJU KOROSI PADA PLAT BAJA LAMBUNG KAPAL DENGAN UMPAN ANODA KORBAN ALUMINIUM
}

\author{
Ngatmin $^{1 *}$, Helmy Purwanto ${ }^{2}$ dan Indah Riwayati ${ }^{3}$ \\ ${ }^{1}$ Politeknik Maritim Negeri Indonesia \\ Jl. Pawiyatan Luhur I, Bendan Duwur, Semarang, Indonesia 50233 \\ ${ }^{2}$ Jurusan Teknik Mesin, Fakultas Teknik, Universitas Wahid Hasyim \\ ${ }^{2} J u r u s a n$ Teknik Kimia, Fakultas Teknik, Universitas Wahid Hasyim \\ Jl. Menoreh Tengah X/22, Sampangan, Semarang 50236 \\ *Email: ngatmin@polimarin.ac.id
}

\begin{abstract}
Abstrak
Pelat lambung kapal merupakan bangunan yang cenderung terjadi kerusakan yang disebabkan oleh korosi karena bersinggungan langsung maupun tidak langsung pada air laut yang bersifat korosif. Penelitian ini bertujuan untuk mengetahui dan menganalisis pengaruh proteksi anode korban aluminium terhadap laju korosi pelat baja lambung kapal dalam kondisi diam dan berputar pada air laut dengan penambahan 3.5\% garam dapur. Pelat baja lambung kapal diberi perlindungan anode I, anode II, anode III dan sebagai kontrol tanpa perlindungan anode korban. Sampel dicelup pada selang waktu 24, 72, 120 dan 168 jam dalam kondisi diam dan berputar pada putaran 14 rpm. Hasil pengujian memperlihatkan korosi dan laju korosi terjadi pada pelat tanpa perlindungan anode baik pada sampel diam maupun pada sampel berputar. Perlindungan katode pada sampel diam menunjukkan laju korosi yang rendah pada pelat baja, sedangkan pada sampel berputar laju korosi terjadi pada pelat walaupun telah diberikan perlindungan. Pada sampel berputar, semakin tinggi laju korosi pada anode korban maka semakin rendah laju korosi pada pelat baja yang dilindunginya.
\end{abstract}

Kata kunci: anode aluminium, perlindungan katodik, plat lambung Kapal

\section{PENDAHULUAN}

Korosi merupakan fenomena alamiah yang terjadi pada material logam, dimana korosi merupakan proses kerusakan material karena reaksi kimia atau elektrokimia dengan lingkungannya. Lingkungan tersebut yaitu lingkungan asam, udara, embun, air tawar, air laut, air danau, air sungai dan air tanah. Air laut mempunyai sifat korosif sehubungan dengan kandungan di dalamnya meliputi ion klorida, daya hantar listrik, oksigen, kecepatan aliran, temperatur, fouling, tegangan, pencemaran, silt dan sedimen tersuspensi, deposit yang terbentuk sehingga menyebabkan kerusakan pada plat lambung kapal (Fontana, 1986). Kapal laut secara langsung akan bersentuhan dengan air laut, dimana air laut dengan kandungan garam mampu mempercepat laju korosi walaupun telah diberi lapisan anti korosi. Laju korosi juga meningkat dengan adanya gelombang dan arus laut yang tinggi di mana efek lebih lanjut menyebabkan kerusakan lapisan anti karat, menghasilkan banyak oksigen, mempercepat penetrasi, membuka rongga di permukaan baja ICCP (Impressed Current Cathodic Protection) lebih efektif dibanding dengan sistem SCAP (Sacrificial Anode Cathodic Protection) SCAP biayanya lebih mahal dibanding ICCP (Wiludin Soepomo, 2013).

Pengendalian korosi pada pelat lambung kapal yaitu dengan mencegah kontak dengan air dengan cara di cat, perlindungan katoda, katoda merupakan elektroda dengan potensial negatif terhadap anoda. Katoda adalah ujung akhir elektron masuk dalam sistem. Katoda merupakan kutub negatif dari sel elektrolit. Baja pelat lambung kapal yang dilapisi atau dihubungkan dengan logam lain yang lebih aktif akan membentuk sel elektrokimia dengan baja sebagai katoda. Baja berfungsi hanya sebagai tempat terjadinya reduksi oksigen. Logam lain berperan sebagai anoda dan mengalami reaksi oksidasi. Dalam hal ini baja sebagai katoda, terlindungi oleh logam lain (sebagai anoda, dikorbankan).

Baja akan terlindungi selama logam pelindungnya masih ada atau belum habis. Proses Galvanisasi (pelapisan dengan Zinc) dapat melindungi besi dari korosi. Besi yang kontak dengan zinc akan membentuk sel elektrokimia dengan besi sebagai katoda. Dengan demikian besi terlindungi dan zinc yang mengalami oksidasi (berkarat) sebagai anoda korban. Sacrificial Protection (pengorbanan anoda) di 
kapal yaitu anoda paduan seng, Zinc anoda adalah elektroda bisa berupa logam maupun penghantar listrik, Sel elektrokimia yang ter polarisasi jika arus listrik mengalir ke dalamnya. Arus listrik mengalir berlawanan dengan arah pergerakan elektron. Pada proses elektrokimia baik sel galvanis (baterai) maupun sel elektrolisis, anoda mengalami oksidasi.

Anoda paduan

aluminium mengalami korosi dalam air laut diakibatkan oleh lapisan oksida yang bersifat katodik yang selalu membungkus logam itu ketika masih berada di udara bebas. Unsur paduan yang ditambahkan dapat mencegah terbentuknya selaput oksida yang merata, merekat erat dan protektif sehingga kegiatan galvanis terus berlangsung. Berdasarkan permasalahan inilah orang mengembangkan paduan aluminium yang menggunakan seng dan air raksa atau seng dan indium.

Penelitian pengujian korosi telah banyak dilakukan, tetapi menganalisis dan membandingkan laju korosi pada sampel yang diam dan bergerak relatif pada media penyebab korosif belum banyak dilakukan. Tujuan penelitian ini adalah mengetahui dan menganalisis pengaruh proteksi anoda korban aluminium terhadap laju korosi pelat baja lambung kapal dan dipengaruhi oleh gesekan larutan elektrolit.

\section{METODE PENELITIAN}

Bahan spesimen adalah pelat baja karbon rendah dengan cara memotong pelat sebagian dari dok kapal PT JMI (Janata Marina Indah) Semarang dengan ukuran panjang, lebar, tebal adalah 58, 28.5 dan $12 \mathrm{~mm}$, Bahan larutan terdiri dari $\mathrm{N}_{\mathrm{a}} \mathrm{OH}$ dan akuades digunakan sebagai pembersih spesimen dan anoda korban paduan aluminium sesuai dengan standar ASTM G.1-81 tentang standard practice for preparing cleaning and evaluating corrosion test spesiment.

Peralatan Penelitian terdiri dari bak plastik yang digunakan untuk menampung air 15 liter larutan elektrolit (air laut), jangka sorong, takometer, timbangan berat dan teleskop optik. Larutan elektrolit yang digunakan adalah air laut dari laut Jawa yang telah sesuai dengan standar ASTM D1141-98 (standard practice for the preparation of substitute ocean water). Waktu uji selama 144 jam/6 hari (Tsai, 1996). Pengujian laboratorium dilakukan dengan uji celup (immersion corrosion test of metal) ASTM G3172. Berdasarkan pengurangan berat dari pelat lambung kapal dilakukan dengan 2 (dua) metode
Metode celup tetap dan Metode celup diputar .

Metode uji celup tetap dilakukan dengan cara spesimen dan anoda dipasang lalu dilakukan perendaman selama 24 jam, 48 jam, 96 jam, 144 jam masing-masing jeda waktu dilakukan foto makro dan penimbangan spesimen sebelumnya dibersihkan dengan larutan $\mathrm{N}_{\mathrm{a}} \mathrm{OH}$ dan akuades dengan dicelup selama 5 menit lalu dikeringkan dengan pemanas serta ditimbang dan dicatat hasilnya (Sasono dkk., 2014). Metode celup diputar sama dengan celup tetap bedanya spesimen dengan anoda diputar dengan putaran sekitar $14 \mathrm{rpm}$.

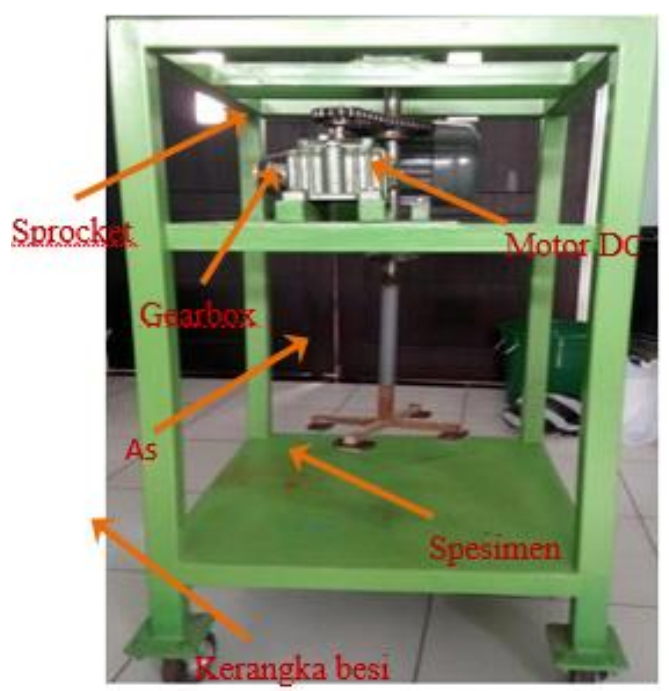

Gambar 1. Alat uji korosi

\section{HASIL DAN PEMBAHASAN}

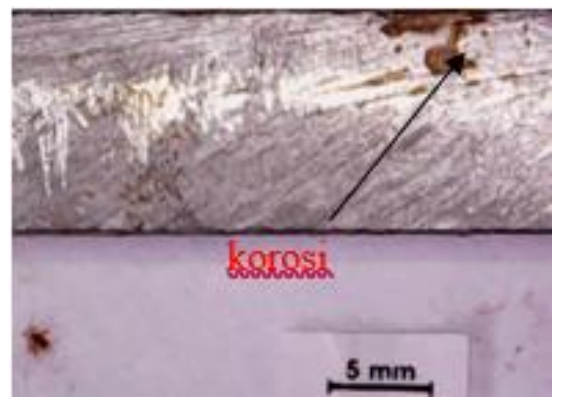

Gambar 2. Korosi korban I pencelupan 24 Jam

Pengamatan Makro pelat Lambung Kapal Pada Gambar 2 korosi terlihat pada anoda korban I dicelup selama 24 jam.

Penambahan anoda korban II korosi baru tampak pada pencelupan 48 jam III, sedangkan pada 24 jam, 48 jam I, 48 jam II tidak tampak 
korosi pada pelat. Korosi pada pelat dengan korosi berat dikarenakan kurangnya kebutuhan anoda korban II seperti terlihat pada Gambar 3.

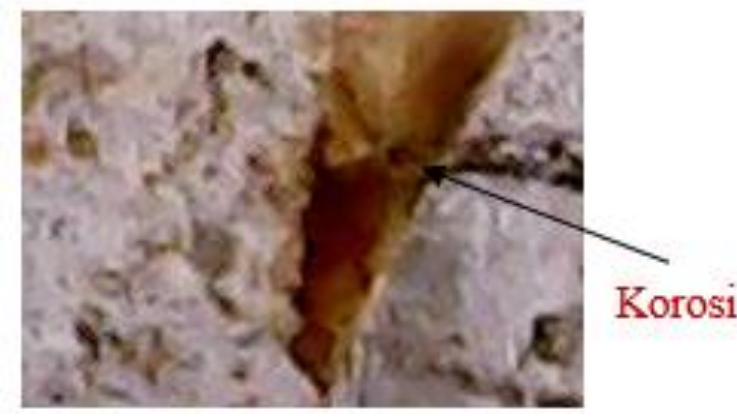

Gambar 3. Korosi yang tampak pada pelat anoda korban I pencelupan 48 Jam III

Penambahan anoda korban III pada setiap perlakuan tidak tampak korosi pada pelat. Hal ini disebabkan pada penambahan anoda korban III diberikan berat anoda yang lebih besar dibandingkan pada anoda korban I dan II.

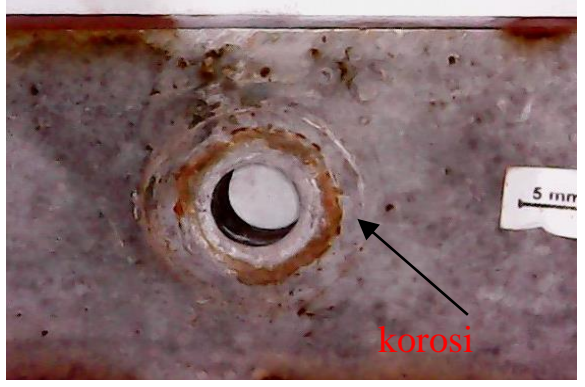

(a)

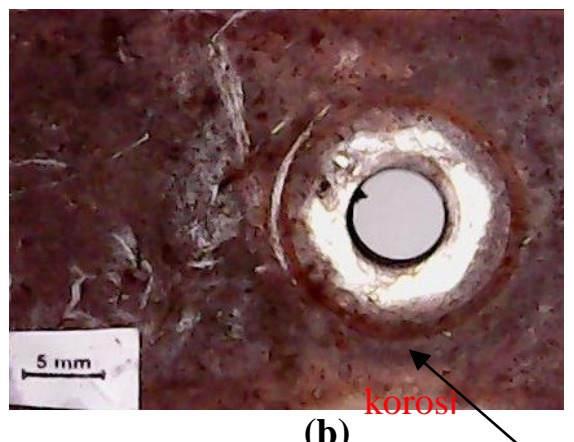

Gambar 4. Korosi yang terlihat pada pelat tanpa anoda korban(a). pencelupan 24 jam (b). pencelupan 48 jam.

Semakin besar atau semakin banyak penambahan anoda korban maka perlindungan korosi pada pelat semakin baik seperti yang telah dilaporkan oleh Sasono, 2014 Dengan perlindungan aluminium menerangkan bahwa industri ditemui lambung kapal yang terserang berat dan jumlah anoda korban yang dipasang.

Pelat tanpa perlindungan anoda korban terlihat korosi pada semua perlakuan yaitu pada pencelupan 24 jam 48 jam I, 48 jam II dan 48 jam III. Tanpa adanya perlindungan dengan anoda korban dapat terjadi pada pelat karena lapisan pelat baja lebih banyak melepas unsur-unsur paduan logam yang mudah terkorosi atau yang tidak tahan terhadap korosi, seperti unsur, sulfat, silikon, mangan dan fosfor, walaupun sedikit kandungannya pada baja, namun pada hari pertama waktu ekspose terjadi laju korosi yang mempunyai kandungan indium sangat tinggi. Dengan adanya anoda korban paduan aluminium maka laju korosi spesimen agak terhambat (Sasono, 2014).

Korosi pada pencelupan 48 jam terlihat lebih banyak dibandingkan pada pencelupan 24 jam. Hal ini disebabkan semakin lama proses pencelupan maka reaksi elektrokimia terjadinya korosi semakin banyak sehingga tampak korosi yang lebih banyak. Korosi pelat tanpa perlindungan anoda korban seperti terlihat pada Gambar 4.

Pengamatan Makro Anoda Korban Aluminium

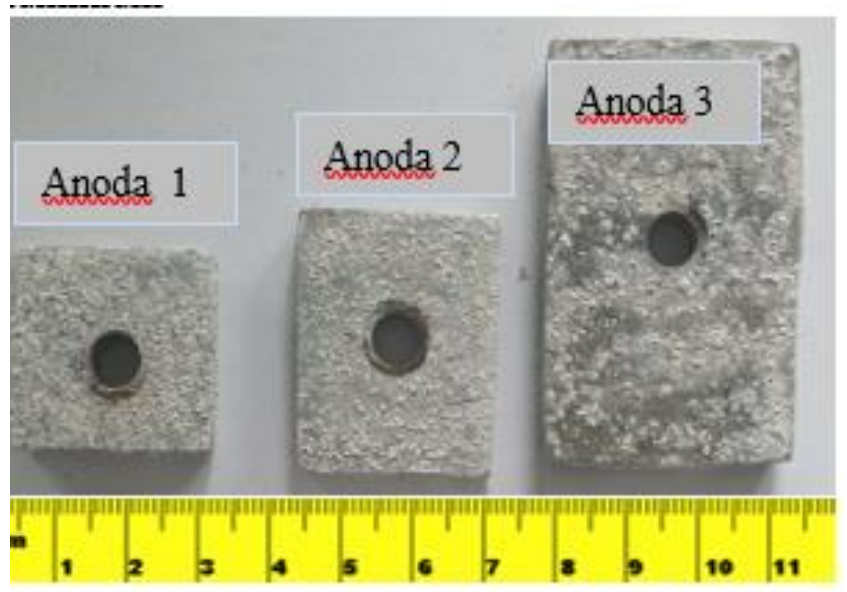

\section{Gambar 5. Bintik - bintik putih pada anoda korban Aluminium}

Dari grafik pada Gambar 6. terlihat bahwa pencelupan selama 24 jam pada spesimen I, II, III dan spesimen tanpa anoda tidak terjadi laju korosi, sedangkan untuk spesimen tanpa anoda terjadi kenaikan laju korosi yang signifikan korosi terjadi pada saat pencelupan selama 72 jam dengan laju korosi 0,02925 mm/tahun, selanjutnya pencelupan selama 120 jam laju 
korosi terjadi kenaikan menjadi 0,035102 $\mathrm{mm} /$ tahun, sedangkan pencelupan selama 168 jam terjadi kenaikan laju korosi menjadi 0,03761 $\mathrm{mm} /$ tahun, laju korosi tertinggi terdapat pada spesimen yang tidak terlindungi oleh anoda korban.

Tabel 1. Hasil penimbangan celup diam

\begin{tabular}{|c|c|c|c|c|c|c|}
\hline \multirow{2}{*}{$N_{0}$} & \multirow{2}{*}{ Nama Spesimen } & \multirow{2}{*}{ Berat awal } & \multicolumn{4}{|c|}{ Waktu } \\
\cline { 3 - 7 } & & & 24 Jam & 48 Jam I & 48 Jam II & 48 Jam III \\
\hline \multirow{2}{*}{1} & Plat 1 & 119.69 & 119.69 & 119.69 & 119.69 & 119.69 \\
\hline & Anoda I & 8.67 & 8.67 & 8.67 & 8.67 & 8.66 \\
\hline \multirow{2}{*}{2} & Plat2 & 117.18 & 117.18 & 117.18 & 117.18 & 117.17 \\
\hline & Anoda II & 9.61 & 9.61 & 9.60 & 9.58 & 9.58 \\
\hline \multirow{2}{*}{3} & Plat3 & 115.09 & 115.09 & 115.09 & 115.09 & 115.09 \\
\hline & Anoda III & 23.78 & 23.78 & 23.77 & 23.75 & 23.73 \\
\hline 4 & Plat 4 & 122.47 & 122.47 & 122.46 & 122.45 & 122.44 \\
\hline & Tanpa anoda & - & - & - & - & - \\
\hline
\end{tabular}

Tabel 2. Hasil penimbangan celup putar

\begin{tabular}{|c|l|c|c|c|c|c|}
\hline \multirow{2}{*}{$N_{0}$} & \multirow{2}{*}{ Nama Spesimen } & \multirow{2}{*}{$\begin{array}{c}\text { Berat } \\
\text { Awal }\end{array}$} & \multicolumn{4}{|c|}{ 24 Jam } \\
\cline { 4 - 7 } & & 24 Jam & 48 Jam I & 48 Jam II & 48 Jam III \\
\hline \multirow{2}{*}{1} & Plat 1 & 118.56 & 118.56 & 118.56 & 118.55 & 118.55 \\
\cline { 4 - 7 } & Anoda I & 8.63 & 8.63 & 8.60 & 8.59 & 8.57 \\
\hline \multirow{2}{*}{2} & Plat2 & 114.56 & 114.56 & 114.55 & 114.55 & 114.54 \\
\cline { 4 - 7 } & Anoda II & 9.53 & 9.53 & 9.51 & 9.49 & 9.47 \\
\hline \multirow{2}{*}{3} & Plat 3 & 113.93 & 113.93 & 113.93 & 113.92 & 113.91 \\
\cline { 4 - 7 } & Anoda III & 23.68 & 23.68 & 23.65 & 23.63 & 23.60 \\
\hline \multirow{2}{*}{4} & Plat 4 & 120.63 & 120.63 & 120.60 & 120.60 & 120.57 \\
\hline & Tanpa Anoda & - & - & - & - & - \\
\hline
\end{tabular}

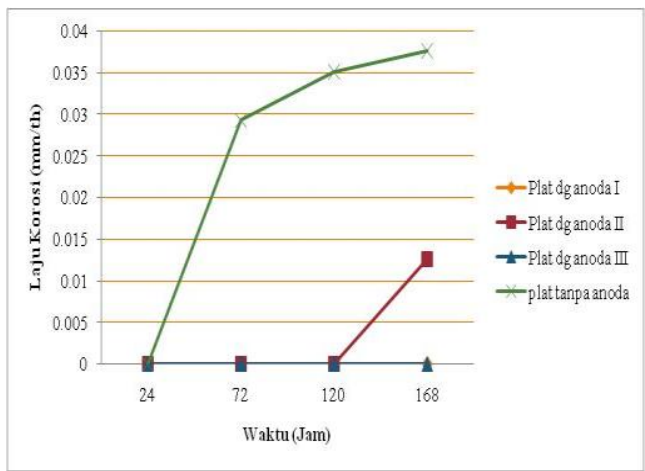

Gambar 6. Grafik laju korosi spesimen diam

Laju korosi terendah terjadi pada spesimen I dan III, untuk spesimen I dengan perlindungan anoda I pencelupan selama 24 jam, 72 jam, 120 jam dan 168 jam tidak terjadi korosi. Selanjutnya untuk spesimen II dengan perlindungan anoda II terjadi korosi dengan laju korosi 0,01254 $\mathrm{mm} /$ tahun dibanding dengan yang terlindungi oleh anoda korban I dan III tidak terjadi korosi.

Dari grafik gambar 7 tampak bahwa tanpa perlindungan anoda korban pada waktu uji celup I selama 24 jam tidak terjadi korosi, korosi tertinggi pada spesimen tanpa anoda korban sedang korosi terendah pada spesimen anoda I. Kenaikan yang signifikan pada waktu pencelupan selama 72 jam dengan laju korosi $0,08776 \mathrm{~mm} /$ tahun. Selanjutnya korosi terjadi penurunan pada waktu 120 jam yaitu 0,052653 $\mathrm{mm} /$ tahun dan pada waktu 168 terjadi kenaikan laju korosi yaitu $0,07522 \mathrm{~mm} /$ tahun, sedangkan untuk spesimen I pencelupan selama 24 jam dan 72 jam tidak tampak terjadi korosi, pada saat pencelupan selama 120 jam korosi baru terjadi sebesar 0,01755 dan selama 168 terjadi penurunan sebesar $0,01254 \mathrm{~mm} / \mathrm{tahun}$.

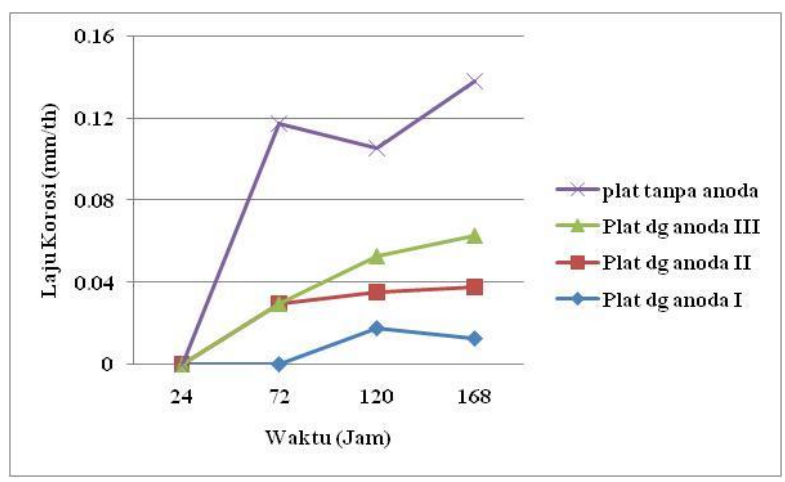

\section{Gambar 7. Grafik laju korosi spesimen berputar}

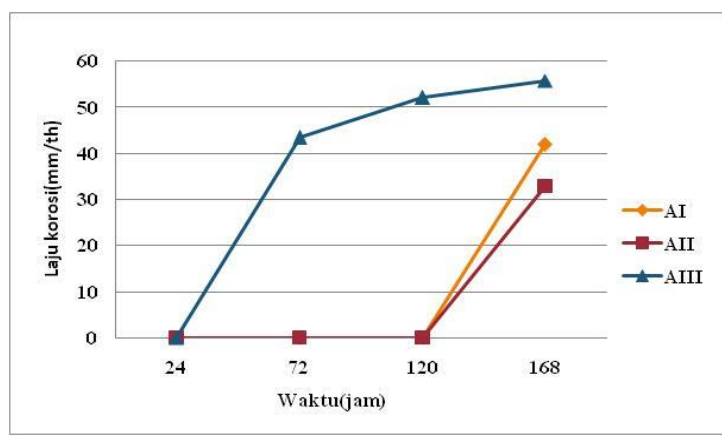

\section{Gambar 8. Grafik laju korosi anoda korban diam}

Spesimen II pencelupan selama 24 jam tidak tampak terjadi korosi korosi terjadi pada saat selama 72 jam dengan laju korosi 0,02925 $\mathrm{mm} /$ tahun, pencelupan 120 jam terjadi penurunan 0,01755 , pencelupan selama 168 terjadi kenaikan menjadi $0,02507 \mathrm{~mm} / \mathrm{tahun}$. Untuk spesimen III pencelupan selama 24 jam dan 72 jam belum tampak terjadi korosi. Laju korosi pada 120 jam dengan laju korosi $0,01755 \mathrm{~mm} / \mathrm{jam}$ dan $168 \mathrm{jam}$ dengan laju korosi 0,02507 mm/tahun. Dengan demikian semakin besar atau semakin berat anoda korban perlindungan laju korosi semakin tinggi begitu juga sebaliknya (Sasono, 2014). 
Dari grafik gambar 8 terlihat bahwa anoda korban I dan II pada pencelupan 24,72 dan 168 jam tidak mengalami pengurangan berat pengurangan berat terjadi pada saat pencelupan 168 jam anoda korban I dengan laju korosi 41.75 $\mathrm{mm} /$ th dan anoda korban II dengan laju korosi $32.80 \mathrm{~mm} / \mathrm{th}$, Sedangkan anoda korban III mengalami pengurangan berat setelah 72 jam dengan laju korosi $43.32 \mathrm{~mm} / \mathrm{th}, 120$ jam dengan laju korosi $51.98 \mathrm{~mm} / \mathrm{th}$ dan $168 \mathrm{jam}$ laju korosinya $55.70 \mathrm{~mm} / \mathrm{th}$.

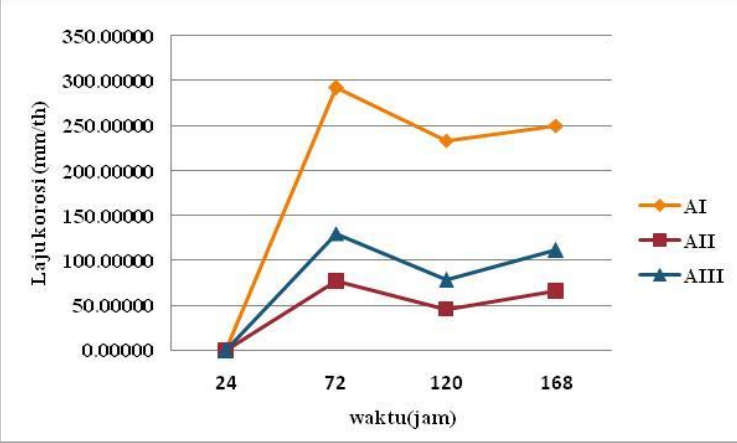

Gambar 9 Grafik laju korosi anoda berputar

Dari tabel 2 pengurangan berat pada anoda korban berputar dapat dilihat pada gambar grafik 9. Anoda korban I, II dan III pada pencelupan 24,72 dan 168 jam tidak mengalami pengurangan berat. Untuk anoda korban I pengurangan berat terjadi pada saat 72 jam dengan laju korosi $292.26 \mathrm{~mm} / \mathrm{th}, 120$ jam dengan laju korosi 233.81 jam dan 168 jam laju korosinya $250.51 \mathrm{~mm} / \mathrm{th}$, anoda korban I laju korosinya lebih tinggi dibanding anoda korban II dan III. Anoda korban II terjadi pengurangan pada saat 72 jam yaitu dengan laju korosi $76.53 \mathrm{~mm} / \mathrm{th}, 120$ jam 45.92 $\mathrm{mm} / \mathrm{th}, 168 \mathrm{jam}$ sebesar $65.60485 \mathrm{~mm} / \mathrm{th}$. Anoda korban III terjadi pengurangan mulai 72 jam dengan laju korosi $129.97 \mathrm{~mm} / \mathrm{th}, 120$ jam 77.98 $\mathrm{mm} /$ th dan 168 jam $111.40 \mathrm{~mm} / \mathrm{th}$. Jadi perbandingan anoda korban celup diam laju korosinya lebih rendah dibanding dengan anoda korban celup diputar, karena anoda korban diputar terjadi gesekan antara anoda korban dengan larutan elektrolit.

\section{KESIMPULAN}

Dari hasil pengujian laju korosi maka dapat disimpulkan bahwa Perlindungan katodik pada pelat baja lambung kapal dengan menggunakan anoda korban aluminium dapat terlindungi dari korosi. Semakin lama waktu pencelupan maka laju korosi semakin tinggi yaitu sebesar $0,037 \mathrm{~mm} /$ tahun lama pencelupan 168 jam pada sampel tanpa perlindungan anoda. Laju korosi pada sampel diam dengan perlindungan anoda terjadi pada plat baja II yaitu sebesar 0,012 $\mathrm{mm} /$ tahun pada waktu pencelupan selama 168 jam. Sedangkan pada sampel diputar laju korosi tertinggi pada sampel III yaitu $0,025 \mathrm{~mm} /$ tahun.

Gesekan pelat dengan larutan berpengaruh terhadap laju korosi baik pada pelat yang diberi perlindungan katodik maupun pelat tanpa perlindungan katodik. Semakin tinggi laju korosi pada anoda korban maka semakin rendah laju korosi pada pelat baja yang dilindungi anoda korban terlihat bahwa laju korosi pada sampel pelat baja diputar sebesar $0,012 \mathrm{~mm} / \mathrm{tahun}$ sedangkan untuk laju korosi pada anoda korbannya sebesar $250,512 \mathrm{~mm} /$ tahun.

\section{DAFTAR PUSTAKA}

Anggono, Juliana. Citro, Soejono Palapessy dan Victor Rizal, 2000, "Studi Perbandingan Kinerja Anoda Korban Panduan Aluminium dengan Panduan Seng dalam lingkungan Air Laut" Jurnal Teknik Mesin Fakultas Teknologi Industri, Universitas Kristen Petra, Surabaya, Volume 2 Nomor 1, Halaman 89-99.

ASASTM G71-81, 2011, Annual Book "Standard Practice for Operation Salt Spray Apparatus" ASTM International, New York

ASTM, G31-72, Annual Book "Standard Pratice for the Preparation of Substitute Ocean Water"New York.USA.

Pongsapan dan Suhadi, 2014 "Efektivitas Penggunaan Anoda Korban Paduan Seng Pada Pelat Baja Kapal AISI E 2512 Terhadap Laju Korosi di dalam media Air Laut" Jurnal Teknik Mesin Fakultas Teknologi Industri

Fontana dan Mars G,1986, Corrosion Engineering, 3rd Edition, Mc Graw Hill Book Co, New York.

Leonard, 2015 "Distribusi tingkat karat dan laju korosi Baja ST 37 dalam lingkungan air laut dan air tawar" Jurnal Teknik Mesin Universitas Hasanuddin Makassar, volume 6 halaman 566.

Pongsapan Universitas Balik papan volume 1 halaman 41-44.

Sasono,EJ,2014"Perhitungan Laju Korosi Plat Lambung Kapal dengan Anoda Korban Panduan Aluminium"Laporan Tesis S2 
Teknik Mesin Universitas Diponegoro Semarang.

Tsai, Tai Ming, 1995, "Protection of Steel Using Aluminium Sacrificial Anodes in Artificial Seawater" Journal of Marine Science and Technology, Volume 4, No 1, tahun 1995, hal 17- 21.

Wiludin dan Soepomo, 2013 “Analisa Teknis dan Ekonomis Penggunaan ICCP (Impressed Current Cathodic Protection) dibandingkan dengan SCAP (Sacrificial anode Cathodic Protection) dalam proses pencegahan korosi" Jurnal, Teknik Perkapalan Fakultas Teknik Kelautan Institut Teknologi Sepuluh November Surabaya. Volume 2 Halaman 3-5. 